\title{
Belgian vs. Netherlandic Dutch - language (variety) awareness among Polish students of Dutch
}

\begin{abstract}
Language Awareness has been defined as "a person's sensitivity to and conscious awareness of the nature of language and its role in human life" (Donmal 1985: 7), The nature of this definition is too broad (Thornbury 1997), allowing for a large number of possible interpretations. Various attempts have been made to narrow down the scope. L. Andrews, for instance, introduced a Language Exploration and Awareness approach to language teaching and learning, stressing, among others, that "students become aware when they have opportunities to explore the distinctions among regional and social varieties" (1998: 6). By extension, this may refer to linguistic varieties as well. Two such varieties of the same language, Dutch, are the ones used in Belgium and the Netherlands (Vandekerckhove 2005). This article examines whether Polish students of Dutch are able to distinguish, i.e. are aware of the differences, between the aforementioned varieties of Dutch when used by native speakers. The results are discussed, among others, within the scope of one of the domains of Language Awareness and from the point of view of explicit (vs. implicit) language learning. Also, some pedagogical implications are provided.
\end{abstract}

\section{Introduction}

According to most sources, the notion of language awareness, in literature often capitalized (Language Awareness) and referred to by its abbreviation LA, dates back to at least 1973, when Hawkins called for "a new subject, 'language', to be taught as a 'bridging subject', linking English and the foreign language in the curriculum" (Hawkins 1999: 124). The aim was to link different aspects of language education, including English as a native tongue, English as a foreign or second language, other foreign languages and minority mother tongues, by breaking down the barriers between them (Hawkins 1999). This came at a time when, as a reaction to Chomsky's Language Acquisition Device hypothesis, there was "a taboo [...] on formal language instruction and talk about language" (Hawkins 1999: 124). 
In recent years, Language Awareness, which is cognitive in nature and has a number of definitions, all of which have the notion of explicit knowledge in common, has evolved into an approach with the aim to make people sensitive to language, its nature and significance in everyday life. In fact, "language awareness, as an educational goal, holds that it is necessary (or at least useful) at times to focus systematically on language in the $[\ldots]$ sense of focal awareness. The two main reasons for this $[\ldots]$ are:

- to deal with problems that occur in the language-using process;

- to reach higher levels of understanding and use" (van Lier 1995: 4).

In this study, I examined, by means of a questionnaire and two extended verbal guises, how (language) (variety) aware Polish students of Dutch are of the differences between Belgian and Netherlandic Dutch when these two varieties are used by native speakers. In the sections that follow I give the theoretical underpinnings of language awareness, including its definitions, domains and the differences between explicit and implicit knowledge. Next, I describe the methodology used and present the results. Finally, the results are discussed within the scope of one of the domains of Language Awareness and from the point of view of explicit and implicit language learning. Also, some pedagogical implications are provided.

\section{Theoretical underpinnings}

\section{Definitions and descriptions}

The term Language Awareness has proven difficult to define. One of the main underlying reasons for this is that work on LA is rooted in a wide array of fields of study, including linguistics, psychology, and education, to name but a few (Pinto et al. 1999), so most definitions, or descriptions, are either too broad in nature or too detailed.

Since the present study is set in an educational context, it seems worth approaching LA from the point of view of teaching and teachers as well as learning and learners (van Essen 2008). Two definitions therefore serve as a base for the present deliberations. One is taken from the article "Ten questions about language awareness", in which one of the authors, Tomlinson, states:

Language Awareness is a mental attribute which develops through paying motivated attention to language in use, and which enables language learners to gradually gain insights into how languages work. It is also a pedagogic approach that aims to help learners to gain such control (Bolitho et al. 2003: 251).

The other definition of Language Awareness can be found on the website of the Association for Language Awareness: "We define Language Awareness as 
explicit knowledge about language, and conscious perception and sensitivity in language learning, language teaching and language use" (ALA 2015).

In other words, within the framework of this particular study, language awareness, contrary to common practice, does not refer to metalinguistic awareness as such but to the awareness of linguistic varieties, that is two varieties, Belgian and Netherlandic, of the same language, Dutch.

\section{The domains of Language Awareness}

Language Awareness is a holistic concept, within which James and Garrett (1991: 12-20) identified 5 domains that determine the learner's language competence and understanding. These are: the affective domain, the social domain, the 'power' domain, the cognitive domain and the performance domain (see also Baker and Prys Jones 1998). The domain that is most relevant to the present study (see Discussion and conclusions) is the affective domain, which relates to the awakening and/or development of attitudes, attention, sensitivity, curiosity and interest.

\section{Explicit knowledge versus implicit knowledge}

The term explicit knowledge "appears in all three original aims of the journal Language Awareness" (S. Andrews 2007: 13) as well as in one of the definitions of Language Awareness quoted above.

This repetitive use of the word 'explicit' is indicative of the assumption that, within the framework of second language acquisition, there is a distinction between conscious and unconscious or, put differently, explicit and implicit knowledge about language. In Second Language Acquisition, explicit knowledge is, in other words, "the declarative and often anomalous knowledge of the phonological, lexical, grammatical, pragmatic, and sociocritical features of an L2" (Ellis 2004: 244). Ellis (2004) adds that it is conscious knowledge that can be learned and verbalized.

In practice this means that this knowledge is resorted to when there is a "linguistic difficulty in the use of the second language" (Ellis 2004: 245), or, for instance, that a learner may be able to correct errors by either describing what is wrong or by using appropriate terminology. The latter is referred to as metalingual knowledge ${ }^{1}$.

O'Malley and Chamot (1990), in focusing on the distinction between declarative (explicit) knowledge and procedural (implicit) knowledge, offer an alternative description of linguistic awareness in cognitive theory: after becom-

${ }^{1} \mathrm{~S}$. Andrews defines metalingual knowledge as "knowledge of the technical terminology for labeling those linguistic and socio-critical features" (2007: 13). 
ing aware of the fact that the same concept is expressed in different ways in L1 and L2, a person establishes a new schema "that differentiates applications of each language to identical concepts" (O'Malley and Chamot 1990: 72).

Explicit knowledge, however, cannot be fully defined or understood without looking at implicit knowledge.

Implicit knowledge, as Ellis posits, "is procedural, is held unconsciously and can only be verbalized if it is made explicit. It is accessed rapidly and easily and thus is available for use in rapid, fluent communication" (2005b: 13). Ellis (1994: 355-356) distinguishes between two types of implicit knowledge: formulaic knowledge, which he calls "ready-made chunks of language", and rule-based knowledge. The latter "consists of generalized and abstract structures which have been internalized".

The relationship between explicit and implicit knowledge is traditionally discussed in terms of the interface between them. This is often referred to as the 'interface hypothesis' (see, for example, Richards and Schmidt 2010). Ellis (2005a, 2005b) distinguishes three interface positions: the non-interface, strong interface and weak interface position. One of the scholars that early on argued in favor of the non-interface position was Krashen, who used a different taxonomy to describe the two processes involved in developing knowledge of a second language (Krashen 1981). His terms are 'acquisition' (implicit knowledge) and 'learning' (explicit learning). Krashen saw no interface between acquisition and learning arguing, for instance, that if learners have explicit knowledge of a rule, meaning that they have learned it and could even quote it, they may not acquire it, that is use it implicitly (Rebuschat and Williams 2012). The strong interface position assumes that explicit and implicit knowledge can both influence and be converted into each other (Ammar et al. 2010). Finally, according to the weak interface position, as explained by Ellis (2005b: 14), "explicit knowledge of a grammatical structure makes it more likely learners will attend to the structure in the input and carry out the cognitive comparison between what they observe in the input and their own output".

\section{Methodology}

\section{Research context}

(1) Teacher: Wat doe je in je vrije tijd? 'What do you do in your free time?' Student: Ik drink een pintje. 'I drink a pint.'

Teacher: En met wie drink je dat pilsje? 'And who do you drink that beer with?'

Student: Pilsje? Nee, pintje. 'Beer? No, a pint.' 
This is how in 2010 first-year students of Dutch at Adam Mickiewicz University (Poznań, Poland) first became acquainted with the lexical differences between two varieties of the Dutch language, namely Belgian and Netherlandic (for an overview of differences between Netherlandic and Belgian Dutch, see de Louw forthcoming). The confusion stemmed from the fact that early on in their Practical Dutch course they had learned the Belgian Dutch word pintje 'beer' or 'a pint' in a class taught by a Flemish teacher. They then used this word quite freely and willingly in a more speaking-focused Practical Dutch class taught by a native speaker of Netherlandic Dutch until they were confronted with the Netherlandic Dutch equivalent, pilsje $^{2}$, as in the example above. Once they knew both words, using pintje still seemed more natural to them as it was the first word they often wanted to use when talking about drinking beer on a night out with friends, even in the aforementioned speaking-focused Practical Dutch class. However, because they felt, or even believed, it was inappropriate to use a Flemish word when speaking to a Dutchman, they gradually replaced it with pilsje. In fact, having uttered a sentence with the Flemish word, they would sometimes quickly change it into the Netherlandic Dutch equivalent, as if self-correcting a mistake. At the same time, when asked directly which variety they preferred, at least in the first semester, quite a few students still seemed to favor Belgian Dutch.

Since these choices and seemingly conscious changes may well have been early signs of the students' (language) awareness ('I'll use pilsje when in my Practical Dutch class taught by a Dutch teacher but pintje in my class taught by a Flemish teacher), the main motivation for the present study was to examine how aware Polish students of Dutch really are of the differences between Netherlandic and Belgian Dutch (for a discussion on the importance of work on language awareness, see Discussion and conclusions).

\section{Research questions and hypotheses}

Based on the observations described above, the following main research question and a number of supplementary questions were posed: How aware are Polish students of Dutch of the differences between two varieties of the Dutch language, namely Belgian and Netherlandic Dutch?

a. Can they identify native speakers of the two varieties when listening to them read or speak?

${ }^{2}$ Both in Belgian and Netherlandic Dutch the diminutive form of the noun is used. Diminutive forms are common in Standard (Belgian and Netherlandic) Dutch. The Belgian Dutch, or Flemish, word 'pintje', meaning 'beer', looks like the English word 'pint' but the pronunciation differs in that the stem rhymes with 'hint'. The Netherlandic Dutch word 'pilsje' is the diminutive form of 'pils', which means 'beer' or 'lager'. 
b. How consistent are the participants in their recognitions of the language variety used as well as the gender of the speakers?

c. Are there any differences in awareness at the level of language proficiency?

d. Are there any differences in awareness depending on gender?

The hypotheses/assumptions for these questions were that:

- advanced learners, who on average had (had) much more experience with and exposure to the two varieties of Dutch, were expected to outperform the beginners across the board by noticing the various linguistic hints in the text (pronunciation) and films (pronunciation, grammar and lexis) and hence identifying more speakers of Netherlandic and Belgian Dutch correctly;

- those with more experience with and better self-reported knowledge of foreign languages would be more sensitive linguistically and therefore better at recognizing the correct variety as they could draw on their knowledge of other language and their varieties ${ }^{3}$;

- there would not be any between-gender variation in awareness, and the respondents would be consistent in their choices and answers.

\section{Participants}

The participants in the study were 34 students (18 female, 16 male) of Dutch at Adam Mickiewicz University in Poznań. They were divided into 2 groups: 19 beginners ( 9 female, 10 male) and 15 (more) advanced participants ( 9 female, 6 male). The beginners' mean age was 21.3, while that of the (more) advanced participants 23.7.

Using the Common European Framework of References for Languages, often abbreviated to CEF or CEFR, and going by these students' results of the Certificaat Nederlands als Vreemde taal [Certificate Dutch as a Foreign Language], the beginners can be classified as A1 and the (more) advanced learners as B2-C1, depending on whether they are $3 \mathrm{BA}$ or $1 \mathrm{MA}^{4}$ students.

Admittedly, a total of 34 participants is rather low, giving the risk of the results not being objective or comprehensive enough. However, such a situation is not unusual as there are various studies that were also done with a low number of participants, such as Leow (1997) with 28, Leow (2000) with 32 and Williams (2004) with 37. These studies show it is possible to draw meaningful conclusions from studies conducted on a small sample.

\section{Beginners}

When the experiment started, the beginners had been learning Dutch ${ }^{5}$ for 6.5 months on average.

\footnotetext{
${ }^{3}$ For example, Britsh English vs. American English or Spanish vs. Catalan.

${ }^{4} \mathrm{BA}=$ bachelor; $\mathrm{MA}=$ master.

${ }^{5}$ Here treated collectively, without a distinction into its varieties.
} 
As far as other foreign languages are concerned, all 19 beginners claimed to know at least one. They four most frequently learned languages they listed were English (all 9 females and all 10 males), German (4 females and 7 males), French ( 2 females and 5 males) and Spanish ( 3 females and 1 male). Other languages included Portuguese, Afrikaans, Italian, Korean, Chinese, Catalan and Latin.

The self-assessed levels of proficiency are presented in Table 1. The scale used ranged from 1 to 5, where 1 meant native-speaker-like competence and 5 very badly.

Table 1. Self-assessed proficiency in other foreign languages according to gender and overall - beginners

\begin{tabular}{|l|c|c|c|}
\hline \multirow{2}{*}{ Languages } & \multicolumn{3}{|c|}{ Participants - means } \\
\cline { 2 - 4 } & Female & Male & Overall \\
\hline English $\left(N=9+10^{6}\right)$ & 2.1 & 2.1 & 2.1 \\
\hline German $(N=4+7)$ & 2.5 & 3.6 & 3.2 \\
\hline French $(N=2+5)$ & 3.0 & 5.0 & 4.4 \\
\hline Spanish $(N=3+1)$ & 3.0 & 2.0 & 2.75 \\
\hline
\end{tabular}

There are a few conclusions that can be drawn from Table 1:

- English was the only other foreign language all participants had learned,

- the female and male participants assessed their knowledge of English equally,

- the participants' level of competence was assessed higher for Germanic languages than for Romance languages,

- in general, females self-assessed their knowledge of foreign languages higher than males did. One exception was Spanish but, as an aside, only one male claimed to know this language.

There was considerable overlap between how well participants knew different languages and the time they spent learning them. On average, they had been studying English, the language they believed to be the most competent in, for over 11 years, German for 8 years, Spanish for over 4 years, and French for almost 3 years. Put differently, their level of proficiency was often directly proportional to the time they spent learning the language.

As far as exposure to and experience with (Netherlandic and Belgian) Dutch, speakers of Dutch and the Low Countries is concerned, out of the 19 beginners that completed the questionnaire:

- 12 (6 females and 6 males) stated they read in Dutch or Flemish more than just the texts they were required to cover as part of their courses, that is in their free time;

- 15 (7 females and 8 males) asserted they watched films, television or Internet programs in Dutch or Flemish;

${ }^{6}$ For each language, the first number of participants refers to the females and the second one to the males. 
- 9 (6 females and 3 males) declared they listened to radio or Internet programs in Dutch or Flemish;

-9 ( 5 females and 4 males) knew somebody from the Netherlands other than their teachers. 8 ( 5 females and 3 males) kept in touch with them on a regular basis;

- 3 ( 2 females and 1 male) knew and kept in touch with somebody from Flanders other than their teachers;

-10 ( 7 females and 3 males) affirmed that they had been to either the Netherlands or Flanders, or both. Six of those ( 5 females and 1 male) marked the Netherlands, 4 ( 2 females and 2 males) both the Netherlands and Flanders, and none just Flanders.

\section{Advanced learners}

When the experiment started, all advanced learners (females and males) had been learning Dutch ${ }^{7}$ for slightly over 36 months on average.

All informants knew at least one other foreign language. They enumerated the following four most frequently learned languages: English (all 9 females and all 6 males), German (6 females and 3 males), Spanish (5 females and 3 males) and French (1 female and 2 males). Other languages included Japanese and Russian.

The self-assessed levels of proficiency are presented in Table 2 . The scale used ranged from 1 to 5 , where 1 meant native-speaker-like competence and 5 very badly.

Table 2. Self-assessed proficiency in other foreign languages according to gender and overall - advanced learners

\begin{tabular}{|l|c|c|c|}
\hline \multirow{2}{*}{ Languages } & \multicolumn{3}{c|}{ Participants - means } \\
\cline { 2 - 4 } & Female & Male & Overall \\
\hline English $\left(N=9+6^{8}\right)$ & 2.7 & 1.8 & 2.3 \\
\hline German $(N=6+3)$ & 3.3 & 4.0 & 3.6 \\
\hline Spanish $(N=5+3)$ & 4.2 & 4.3 & 4.25 \\
\hline French $(N=1+2)$ & 2.0 & 3.5 & 3.0 \\
\hline
\end{tabular}

Overall, the knowledge of English was self-assessed as closest to that of native speakers. Also, female participants estimated their knowledge of foreign languages higher than males did, except for English. Table 2 does not show any other consistencies.

The answers to the question of how long the participants had studied the different languages ranged from half a year to 23 years. The mean scores for the particular languages were as follows: English close to 12 years, German almost 9 years, Spanish just over 2 years, and French 3.5 years.

${ }^{7}$ Here treated collectively, without a distinction into its varieties.

${ }^{8}$ For each language, the first number of participants refers to the females and the second one to the males. 
As far as exposure to (Netherlandic and Belgian) Dutch, speakers of Dutch and the Low Countries is concerned, out of the 15 (more) advanced learners that completed the questionnaire:

- 14 (all 9 females and 5 males) confirmed they read texts in Dutch or Flemish other than the ones required in their courses;

- all 15 answered 'yes' to the question whether they watched films, television or Internet programs in Dutch or Flemish;

- 7 (5 female and 2 male) listened to radio or Internet programs in Dutch or Flemish; 14 (8 female and 6 male) knew somebody from the Netherlands other than their teachers. Out of those 14 participants, 9 (4 female and 5 male) kept in touch with the person or people from the Netherlands;

-6 (4 female and 2 male) claimed to know somebody from Flanders other than their teachers with only 5 ( 3 female and 2 male) keeping in touch with them;

-12 ( 8 female and 4 male) reported having been to either the Netherlands or Flanders, or both. Seven of them (4 female and 3 male) had visited only the Netherlands, 1 female Flanders, and 4 ( 3 female and 1 male) both.

\section{Measures}

The study consisted of a questionnaire (session one) and two extended verbal guise tasks (sessions two and three). In each verbal guise there were two parts, in the first one of which the participants were expected to determine which variety of Dutch the speakers used, which is how this part helped to determine their awareness, while the second one was the verbal guise itself, with, therefore, clear focus on language attitudes rather than awareness. Since only the two language awareness parts of the verbal guises bear relevance to this paper, the parts pertaining to language attitudes are excluded from deliberations and analysis. Of importance, in the first verbal guise the participants listened to 24 Flemish and Dutch men and women reading the same text (PE 2010). The second verbal guise differed in that they listened to 12 actors and actresses starring in Flemish and Dutch versions of the same 2 films 9 .

\section{Results}

All the results pertaining to task one of the first verbal guise (recognition of the language variety) are presented in Tables 3-6.

${ }^{9}$ Loft, a Belgian, or rather Flemish, thriller directed in 2008 by Erik Van Looy; Loft, the Dutch 2010 remake of the Flemish version, directed by Antoinette Beumer; Alles is Liefde [All is Love], a Dutch romantic comedy directed in 2007 by Joram Lürsem; Zot van A. [Crazy about A.], the 2010 Flemish version of Alles is Liefde, directed by Jan Verheyen. 
Table 3. Summary of recognitions of the language - mean scores for female and male beginners

\begin{tabular}{|l|c|c|c|}
\hline $\begin{array}{c}\text { Number of correct recognitions } \\
\text { presented as mean scores) of the } \\
\text { language used by .. }\end{array}$ & $\begin{array}{c}\text { Female } \\
\text { beginners }(N=9)\end{array}$ & $\begin{array}{c}\text { Male beginners } \\
(N=10)\end{array}$ & $\begin{array}{c}\text { All beginners } \\
(N=19)\end{array}$ \\
\hline ... Flemish females $(N=6)$ & 2.89 & 3.5 & 3.21 \\
\hline$\ldots$ Flemish males $(N=6)$ & 2.67 & 3.7 & 3.21 \\
\hline$\ldots$ Dutch females $(N=6)$ & 4.0 & 4.6 & 4.3 \\
\hline$\ldots$ Dutch males $(N=6)$ & 4.11 & 3.9 & 4.0 \\
\hline$\ldots$ all speakers $(N=24)$ & 13.67 & 15.7 & 14.72 \\
\hline
\end{tabular}

It is clear from Table 3 that both female and male beginners found it easier to recognize Dutch speakers. Interestingly, among the 9 female beginners there was one who failed to recognize any of the 6 female speakers of Belgian Dutch and one that did not recognize any of the 6 male speakers of Belgian Dutch.

On the other hand, one female beginner recognized all 6 female speakers of Netherlandic Dutch, while 3 recognized all 6 male speakers of Netherlandic Dutch. Among the 10 male beginners one failed to recognize any of the Flemish females, while one recognized all 6 Flemish females and one all 6 Dutch females.

In addition, female beginners achieved a higher mean score for their recognition of Dutch males (4.11 against 3.9), while male beginners had a higher score for Dutch females (4.6 against 4.0), which means that when it comes to speakers of Netherlandic Dutch beginners recognized speakers of the opposite sex more easily.

However, this is not true for the beginners' ability to recognize speakers of Belgian Dutch as male beginners achieved a slightly higher mean score for their recognition of male speakers of Belgian Dutch (3.7 against 3.5) and so did female beginners for their recognition of female speakers of Belgian Dutch (2.89 against 2.67).

With male beginners achieving higher scores in 3 categories, their overall score (15.7) was also higher than that for female beginners (13.67).

Table 4. Summary of recognitions of the language - mean scores for female and male advanced learners

\begin{tabular}{|l|c|c|c|}
\hline $\begin{array}{c}\text { Number of recognitions } \\
\text { presented as mean scores) of the } \\
\text { language used by } \ldots\end{array}$ & $\begin{array}{c}\text { Female advanced } \\
\text { learners }(N=9)\end{array}$ & $\begin{array}{c}\text { Male advanced } \\
\text { learners }(N=6)\end{array}$ & $\begin{array}{c}\text { All advanced } \\
\text { participants } \\
(N=15)\end{array}$ \\
\hline$\ldots$ Flemish females $(N=6)$ & 4.22 & 4.83 & 4.47 \\
\hline$\ldots$ Flemish males $(N=6)$ & 3.78 & 4.5 & 4.07 \\
\hline$\ldots$ Dutch females $(N=6)$ & 5.56 & 5.67 & 5.6 \\
\hline$\ldots$ Dutch males $(N=6)$ & 4.78 & 4.83 & 4.8 \\
\hline$\ldots$ all speakers $(N=24)$ & 18.56 & 19.83 & 18.93 \\
\hline
\end{tabular}


Among the advanced learners (Table 4), there are two patterns. One is in the recognitions of female speakers of Netherlandic Dutch, the mean scores for female (5.56) and male (5.67) advanced learners being almost identical and much higher than either group achieved for recognitions of any of the other categories. The other one lies in the fact that both female and male advanced learners scored more correct recognitions when listening to female speakers of both varieties - for female advanced learners the scores were 4.22 for Flemish females against 3.78 for Flemish males and 5.56 for Dutch females versus 4.78 for Dutch males, while for male advanced learners the scores were 4.83 for Flemish females against 4.5 for Flemish males and 5.67 for Dutch females versus 4.83 for Dutch males.

As far as other scores are concerned, female advanced learners did better than their male peers on their recognition of the language used by Dutch males (4.83 against 4.67) but they did worse on Flemish females (4.22 against 4.83) and Flemish males (3.78 against 4.5). This in a way gives a third pattern because with the scores for the recognitions of female speakers of Netherlandic Dutch, albeit almost identical, being slightly higher for female beginners ( 5.56 versus 5.67 , as was mentioned before), both female and male speakers of Netherlandic Dutch are recognized slightly more easily by female advanced learners, while both female and male speakers of Belgian Dutch are recognized more easily among male advanced learners.

The overall score for male advanced learners (19.83) was higher than the one for female advanced learners (18.56).

To determine whether there is a significant statistical difference between the scores, a Chi-square test was run.

Table 5. Statistical analysis of the number of recognitions in session two of the study - according to level of proficiency

\begin{tabular}{|l|c|c|}
\hline \multicolumn{1}{|c|}{ Number of recognitions of $\ldots$} & Beginners $(N=19)$ & Advanced learners $(N=15)$ \\
\hline$\ldots$ FLEMISH as Dutch. & 106 & 50 \\
\hline$\ldots$ FLEMISH as Flemish. & 122 & 130 \\
\hline \multicolumn{3}{|c|}{ Chi-square $=14.92 ; d f=1 ; p=.001 *$} \\
\hline$\ldots$ DUTCH as Dutch. & 158 & 155 \\
\hline$\ldots$ DUTCH as Flemish. & 70 & 24 \\
\hline \multicolumn{2}{|c|}{ Chi-square $=16.88 ; d f=1 ; p=<.001 *$} \\
\hline Correct answers & 280 & 285 \\
\hline Incorrect answers & 176 & 74 \\
\hline \multicolumn{2}{|c|}{ Chi-square $=30.55 ; d f=1 ; p=<.001 *$} \\
\hline
\end{tabular}

All comparisons of the results presented in Table 5 show statistically significant differences in the number of recognitions of both varieties among beginners and advanced learners. 
However, when analyzing how many of the 24 speakers were correctly recognized, the results show that even though advanced learners outperformed beginners on 18 counts (where one count indicates one speaker), they did so by a large margin only on 7 (in the case of 1 Dutch man, 3 Dutch women and 3 Flemish women). Also, beginners outperformed advanced learners on 3 counts and they performed as well as advanced learners on 3 counts as well, making the results less clear-cut than the statistical analysis indicates.

Contrary to expectations, there is one statistically significant difference between female and male participants (Table 6), namely when comparing the number of recognitions of Flemish as Flemish and the number of misrecognitions of Flemish as Dutch. None of the other comparisons, however, give statistically significant differences.

Table 6. Statistical analysis of the number of recognitions in session two of the study — according to gender

\begin{tabular}{|l|c|c|}
\hline \multicolumn{1}{|c|}{ Number of recognitions of $\ldots$} & Females $(N=18)$ & Males $(N=16)$ \\
\hline$\ldots$ FLEMISH as Dutch. & 93 & 63 \\
\hline ... FLEMISH as Flemish. & 123 & 129 \\
\hline \multicolumn{3}{|c|}{ Chi-square $=4.52 ; d f=1 ; p=.0336^{*}$} \\
\hline$\ldots$ DUTCH as Dutch. & 170 \\
\hline$\ldots$ DUTCH as Flemish. & 49 & 447 \\
\hline \multicolumn{2}{|c|}{$C h i$-square $=0.07 ; d f=1 ; p=.7979$} \\
\hline Correct answers. & 293 & 276 \\
\hline Incorrect answers. & 142 & 108 \\
\hline \multicolumn{2}{|c|}{$C h i$-square $=1.96 ; d f=1 ; p=.1611$} \\
\hline
\end{tabular}

All the results pertaining to task one of the second verbal guise (recognition of the language variety) are presented in Tables 7-10.

Table 7. Correct recognitions of the language variety — mean scores for female and male beginners

\begin{tabular}{|l|c|c|c|}
\hline $\begin{array}{c}\text { Number of recognitions (presented } \\
\text { as mean scores) of the language } \\
\text { used by ... }\end{array}$ & $\begin{array}{c}\text { Female begin- } \\
\text { ners } \\
(N=9)\end{array}$ & $\begin{array}{c}\text { Male beginners } \\
(N=10)\end{array}$ & $\begin{array}{c}\text { All beginners } \\
(N=19)\end{array}$ \\
\hline .. Flemish females $(N=3)$ & 1.11 & 1.3 & 1.21 \\
\hline ... Flemish males $(N=3)$ & 1.11 & 1.4 & 1.26 \\
\hline$\ldots$ Dutch females $(N=3)$ & 2.22 & 2.0 & 2.11 \\
\hline .. Dutch males $(N=3)$ & 2.0 & 1.8 & 1.89 \\
\hline$\ldots$ all speakers $(N=12)$ & 6.44 & 6.5 & 6.47 \\
\hline
\end{tabular}


Both female and male beginners found it easier to recognize Dutch speakers. In addition, female beginners scored higher than males on recognitions of female and male speakers of Netherlandic Dutch. However, male beginners scored higher than their female peers on recognitions of male and female speakers of Belgian Dutch.

Interestingly, among the 9 female beginners and 10 male beginners, there were quite a few participants who failed to recognize any of the speakers of Belgian Dutch, female or male. However, none of the participants, female or male, failed to recognize any of the speakers of Netherlandic Dutch. In fact, among the female beginners, 5 out of 9 recognized all 3 Dutch females and 3 did likewise with all 3 Dutch males, while only one female beginner recognized all 3 Flemish females and none the Flemish males. Among the male beginners, there were fewer full scores with 1 recognizing all Flemish females, 1 all Flemish males, 1 all Dutch females and 2 all Dutch males.

The mean number of correct recognitions of the language variety spoken by the 12 speakers for male beginners (6.5) and female beginners (6.44) was almost identical.

Table 8. Correct recognitions of the language variety - mean scores for female and male advanced learners

\begin{tabular}{|l|c|c|c|}
\hline $\begin{array}{c}\text { Number of recognitions } \\
\text { presented as mean scores) of the } \\
\text { language used by } \ldots\end{array}$ & $\begin{array}{c}\text { Female advanced } \\
\text { learners }(N=9)\end{array}$ & $\begin{array}{c}\text { Male advanced } \\
\text { learners }(N=6)\end{array}$ & $\begin{array}{c}\text { All Advanced } \\
\text { learners }(N=15)\end{array}$ \\
\hline$\ldots$ Flemish females $(N=3)$ & 2.22 & 2.33 & 2.27 \\
\hline$\ldots$ Flemish males $(N=3)$ & 2.33 & 1.67 & 2.07 \\
\hline$\ldots$ Dutch females $(N=3)$ & 2.44 & 3.0 & 2.67 \\
\hline$\ldots$ Dutch males $(N=3)$ & 2.44 & 1.67 & 2.13 \\
\hline$\ldots$ all speakers $(N=12)$ & 9.44 & 8.67 & 9.13 \\
\hline
\end{tabular}

Among the advanced learners (Table 8), again, two patterns are discernable. One is that there is very little within-group variation among the female advanced learners with scores ranging from 2.22 to 2.44 , while the scores for male advanced learners ranged from 1.67 to 3.0. The other pattern lies in the male advanced learners being much better at recognizing female speakers of both Belgian and Netherlandic Dutch (2.33 and 3.0 respectively) than the male peers (1.67 and 1.67 respectively).

It is interesting to note that all 6 male advanced learners were able to recognize all 3 Dutch females. Also, the overall score for female advanced learners (9.44) was higher than that for male advanced learners (8.67).

To determine whether there is a significant statistical difference between the scores presented in the tables above, a Chi-square test was run. 
Table 9. Statistical analysis of the number of recognitions in session two of the study - according to level of proficiency

\begin{tabular}{|l|c|c|}
\hline $\begin{array}{c}\text { Number of recognitions of } \\
\ldots\end{array}$ & Beginners $(N=19)$ & Advanced learners $(N=15)$ \\
\hline$\ldots$ FLEMISH as Dutch & 65 & 25 \\
\hline ... FLEMISH as Flemish & 49 & 66 \\
\hline \multicolumn{2}{|c|}{$C h i$-square $=17.44 ; d f=1 ; p=<.001^{*}$} \\
\hline$\ldots$ DUTCH as Dutch & 78 & 73 \\
\hline$\ldots$ DUTCH as Flemish & 36 & 17 \\
\hline \multicolumn{2}{|c|}{$C h i$-square $=4.21 ; d f=1 ; p=.0402^{*}$} \\
\hline Correct answers & 127 & 138 \\
\hline Incorrect answers & 101 & 42 \\
\hline \multicolumn{2}{|c|}{} \\
\hline
\end{tabular}

All comparisons for beginners and advanced learners (Table 9) show statistically significant differences. However, when analyzing how many of the 12 speakers were correctly recognized, the results show that advanced learners outperformed beginners only on 7 counts (where one count indicates one speaker), including 5 by a large margin (Dutch Woman - 1; Flemish woman - 2; Flemish man - 2). With beginners outperforming advanced learners on one count and performing just as well as advanced learners on 4 counts, the conclusion is the same as before: the results are less straightforward than is indicated by statistical analysis.

Table 10. Statistical analysis of the number of recognitions in session two of the study - according to gender

\begin{tabular}{|l|c|c|}
\hline $\begin{array}{c}\text { Number of recognitions of } \\
\ldots\end{array}$ & Females $(N=18)$ & Males $(N=16)$ \\
\hline ... FLEMISH as Dutch & 46 & 43 \\
\hline ... FLEMISH as Flemish & 62 & 53 \\
\hline \multicolumn{2}{|c|}{$C h i$ square $=0.1 ; d f=1 ; p=.7519$} \\
\hline ... DUTCH as Dutch & 84 & 67 \\
\hline$\ldots$ DUTCH as Flemish & 24 & 29 \\
\hline \multicolumn{2}{|c|}{ Chi square $=1.69 ; d f=1 ; p=.1942$} \\
\hline Correct answers & 146 & 120 \\
\hline Incorrect answers & 70 \\
\hline
\end{tabular}

None of the comparisons for females and males give statistically significant differences (Table 10). 


\section{Discussion and conclusions}

To determine the level of awareness, the participants were asked to identify speakers of Netherlandic and Belgian Dutch in two extended versions of a verbal guise task. In the first one, the participants listened to speakers of Netherlandic Dutch and Belgian Dutch reading exactly the same text. In the second, they listened to speakers of Netherlandic Dutch and Belgian Dutch, all of whom were actors acting in Dutch and Flemish versions of the same 2 films. The results have been analyzed by participants' language proficiency and gender and tested for consistency.

The hypotheses were that advanced learners would notice the various linguistic hints in the text (pronunciation ${ }^{10}$ ) and films (pronunciation, grammar and lexis) and hence outperform the beginners across the board by identifying more speakers of Netherlandic and Belgian Dutch correctly. In addition, those with more experience with and better self-reported knowledge of foreign languages would be better at recognizing the correct variety. Finally, there would not be any between-gender variation in awareness, and the respondents would be consistent in their choices and answers.

The answer to the question whether Polish students of Dutch are able to distinguish between Belgian and Netherlandic Dutch, which are typologically close but differ substantially in terms of pronunciation, lexis and grammar, is a very tentative yes. The reluctance in providing a fully affirmative answer lies in the fact that even though the participants correctly identified at least half of the speakers, their overall score on all 36 speakers is a mere $68.2 \%$. Furthermore, with the number of clues present in the text and the films, phonetic ones in the case of the former and phonetic, grammatical and lexical ones in the case of the latter, the participants, in particular the advanced ones, should have been able to make a greater number of correct recognitions while at the same time proving to be more aware of the varieties used by the speakers.

Regarding the level of proficiency, all the differences between advanced learners and beginners on the number of correct recognitions versus the number of misrecognitions are statistically significant. Nevertheless, advanced learners did not outperform beginners across the board, which they were expected to do. In fact, on some counts they were outperformed.

One explanation for advanced learners not always outperforming beginners could be that the latter, for whom the content of both the text and the films was beyond full comprehension, based their answers on one or two hints they did manage to pick out, whereas the advanced learners heard too many clues, which could

10 The phonetic hints in the text were present, among others, in the names of politicians and the names of political parties, and included, for instance, the bilabial pronunciation of ' $w$ ' in Belgian Dutch, the different realizations of ' $r$ ' in Belgian and Netherlandic Dutch, diphthongization in Netherlandic Dutch, and the devoicing of fricatives in Netherlandic Dutch. 
have made them confused. Also, if a participant was mainly used to Netherlandic Dutch, then everything that sounded different could have automatically been taken as Belgian Dutch. And vice versa.

Another assumption was that there would be little, if any, between-gender variation in awareness. Surprisingly, however, there in fact is a statistically significant difference in the number of recognitions of Flemish speakers by females and males in part two.

A further hypothesis was that participants who had (had) more experience with and better self-reported knowledge of foreign languages would be better at recognizing the correct variety. This proved partly true. To exemplify, among beginners, participant 1BA17, having learned more languages, including varieties of the same language, than any participant, at either level, indeed scored better on recognitions than all other beginners and as well as the best advanced learners. On the other hand, the scores of participants 1BA6, who had (had) the most exposure to the Dutch language and experience with the target-language community, and 1BA12, who knew more than 3 foreign languages well, were average. Among advanced learners, the scores of participant $3 \mathrm{BA} 8$, who knew the most foreign languages well, are among the highest. From the two participants that had spent a whole semester studying at a Flemish university, 3BA2 and 3BA5, where they were exposed to speakers of Belgian and Netherlandic Dutch as well as those who spoke 'tussentaal'11 on a daily basis, and who were therefore expected to be good at recognizing varieties of Dutch, only student 3BA5 indeed was.

Other comparisons, both between groups and within individual ratings and answers, also indicate some inconsistencies. One example concerns male participants performing better than their female peers on recognizing the appropriate language variety used by the speakers when comparing the summaries of recognitions for beginners and advanced learners in the first verbal guise and for beginners in the second verbal guise but not when scrutinizing the mean scores for advanced learners in the second verbal guise.

Inconsistencies do not only concern the number of correct recognitions. When the scores of two randomly chosen participants, 1BA1 and 1BA2, are compared, it must be concluded that individual results and answers can confirm the overall inconsistencies. Participant 1BA, unlike participant 1BA2, did little work outside the classroom, did not know anybody from the Netherlands or Flanders, had spent very little time in the 2 places and yet their scores on recognitions are comparable. On the other hand, when the results of participant 1BA1 only are scrutinized, it must be stated that she was better at recognizing Belgian Dutch speakers but inconsistent in her assessment. Therefore her results in the experimental sessions

11 'Tussentaal' can be literally translated as intermediate language but in literature it is sometimes referred to as interlanguage (see, for instance, de Caluwe 2004). Jaspers (2001) calls this interlanguage a Flemish substandard variety. "From a structural perspective, it is situated in between the standard variety and the Brabantic dialects of Northern Belgium" (Vandekerckhove 2007: 189). 
were neither in line with what she proclaimed in the questionnaire nor with each other. She was, however, consistent in her characteristic-definition comparisons.

Participant 1BA5's marking Dutch rather than Flemish on 35 out of $36^{12}$ occasions constitutes another example of inconsistency. Nevertheless, in a debriefing interview, this student asserted her answers reflected her beliefs at the time of the study and hence were indicative of how aware she was, making them relevant.

Though unintentionally, linguistic awareness, or lack thereof, appears also to have been examined, albeit to some extent only, in session one of the study, the questionnaire. In its first part (questions 9 and 10), participants were asked to state whether they would prefer to study Belgian or Netherlandic Dutch if given the choice and to justify their answer. Some of the answers exhibit a lack of awareness. For instance, participant 1BA12, having been exposed to native speakers of both varieties and having been explicitly acquainted with at least one lexical difference (see Research context), claimed it was difficult to choose which variety he preferred since he knew nothing about the differences between the two. Participant 3BA1, after about 2.5 years of studying Dutch, stated that Dutch to her meant the Dutch that is spoken on the news, adding that she had never heard of other varieties. Last but not least, participant 1MA3, a fourth-year student of Dutch at the time, declared she did not know there was a division into Belgian and Netherlandic Dutch. Then again, it could be argued that such a view is consistent with Kellerman's psychotypology, according to which languages that are similar to each other are seen as the same (Kellerman 1977).

Some answers to questions 9 and 10 of the first part of the questionnaire, on the other hand, were clear indications of the participants' awareness of language varieties. For instance, participant 1BA14, a beginner, called Netherlandic Dutch the standard variety when justifying the choice he made in reply to question 9.

A different type of linguistic awareness was exhibited by participant 1BA6, who argued it was easier to focus on vocabulary when listening rather than watching for the simple reason of there being no distractors in the former.

Overall, though there are exceptions, the results show that the 34 students of Dutch at Adam Mickiewicz University exhibit a lack of awareness of the two varieties of the language they study, that is Netherlandic and Belgian Dutch. Apparently, and mere exposure to native speaker teachers of either variety is not sufficient to make them conscious (de Louw 2013). Exposing students to the two varieties through the use of two main course books, one for each variety, in Practical Dutch classes or individual work done by the students outside the classroom, visits to the Netherlands and/or Flanders or maintaining a relationship with people from one or both places may not guarantee a score above average, either.

12 This total (36) is the sum of 24 (speakers from session two) and 12 (speakers from session three). 
The findings can also be discussed within the framework of explicit versus implicit knowledge. Some pedagogical implications are intertwined in this discussion.

Explicit and implicit knowledge can, among others, be distinguished by looking at systematicity, which in the case of the former refers to anomalous and inconsistent knowledge and in the case of the latter to variable but systematic knowledge, and at awareness, which in implicit knowledge is intuitive and in explicit knowledge conscious (Ellis 2005a). The implications for this present study may be that overall the participants exhibit a weak interface position between explicit and implicit knowledge (2005a), with some participants able to more or less consciously make use of the knowledge they have of the differences between the two varieties ${ }^{13}$, exhibiting declarative knowledge this way, while others, especially those with very little exposure to either variety, had to rely on intuition, that is their implicit knowledge, more. Also, some participants were good at identifying speakers of Belgian and Netherlandic Dutch correctly in one task but not in another, which may be indicative of their knowledge being inconsistent, which is a feature of explicit knowledge.

Paradis $(2004,2009)$ stresses the importance of consciousness in his explanations of how knowledge and competence operate. Other scholars (Ellis 1994; S. Andrews 2007; Svalberg 2007) also focus on the role consciousness plays in language learning. Following Schmidt's taxonomy (1990), one of the three senses of the term, that is consciousness as awareness, can function at three levels: perception, noticing and understanding. In other words, a learner needs to perceive, albeit on a rather subliminal level, notice, or register, and then understand to become aware. When applying this theory to the findings in the present study, a possible explanation of the participants' lack of awareness may simply be that students of Dutch at Adam Mickiewicz University do not do enough conscious work on the differences and similarities between Belgian and Netherlandic Dutch to be aware of them. And if they do or think they do, it may in fact have little to do with Netherlandic and/or Belgian Dutch stimuli. For instance, when they listen to or watch a music program, with most, if not all, songs in English and the DJ or VJ either not saying much apart from names and titles or speaking a different language than Dutch, the experience does not really raise awareness. Another reason might be that they lack metacommunicative awareness (Scollon and Scollon 2001) as they fail to notice the contextual or linguistic clues present in an interaction. This could be because they lack the ability "to concentrate on some things while ignoring others" (Richards and Schmidt 2010: 38). Put differently, they do not pay attention. After all, attention, a notion Schmidt (2001) adds to the discussion on consciousness and SLA, is needed for long-term memory storage.

${ }^{13}$ For example, participant 1BA17, who made notes on why he had circled 'Flemish' or 'Dutch' in the tasks on recognizing langauge variety. 
Leow posits "that little, if any, learning can take place without attention" (2006: 125). Since more attention leads to more learning, it is axiomatic that the level of consciousness must be raised in order to facilitate this process.

Furthermore, the findings seem to support Fairclough's view that work on awareness cannot be limited to the classroom setting (1996). Though he refers more to metalinguistic knowledge, the argument seems to hold for the ability to differentiate between varieties of a language as well, which is why he calls for Critical Language Awareness, where 'critical' means 'careful' or 'thoughtful'. This, in turn, underlines the value of explicit knowledge.

The findings on awareness also bear relevance on one of the five domains of Language Awareness ${ }^{14}$ (James and Garrett 1991; Baker and Prys Jones 1998), that is the affective domain. It relates to the awakening and/or development of, among others, attention, a notion already discussed in the context of (raising) consciousness.

Finally, work on (language) awareness is important for a variety of reasons, including:

- it may allow learners of a language to notice cultural and linguistic differences more easily and to become more aware of their native language when comparing it to the foreign languages they learn;

- it may contribute to Teacher Language Awareness (Thornbury 1997) as they themselves may become more inquisitive, knowledgeable and, possibly, effective;

- awareness raising activities may, to some extent, exemplify the role of explicit knowledge in the process of developing implicit knowledge and by doing so contribute to the consensus-less discussion on how implicit knowledge can indeed be developed.

\section{References}

ALA: Association for Language Awareness Home Page. Last accessed on 31.08. 2015. <http:// www.languageawareness.org/web.ala/web/tout.php>.

Alles is Liefde (2007): film directed by Joram Lürsen. A-film.

Ammar, Ahlem et al. (2010): “Awareness of L1/L2 differences: Does it matter?" In: Language Awareness 19, 2: 129-146.

Andrews, Larry (1998): Language exploration and awareness: A resource book for teachers. Mahwah: Lawrence Erlbaum Associates.

Andrews, Stephen (2007): Teacher language awareness. Cambridge: Cambridge University Press.

Baker, Colin / Sylvia Prys Jones (1998): Encyclopedia of bilingualism andbilingual education. Clevedon: Multilingual Matters.

Bolitho, Rod et al. (2003): “Ten questions about language awareness.” In: ELT Journal 57, 3: 251259.

14 The five domains are: affective, social, 'power', cognitive and performance. 
de Caluwe, Johan (2004): "Conflicting language conceptions within the Dutch speaking part of Belgium.” In: Trans: Internet-Zeitschrift für Kulturwissenschaften 25, 6.1: 53-58.

de Louw, Robertus (2013): "Dutch as spoken in Belgium Differs from the variety spoken in the Netherlands. Or does it? Awareness and assessment of speech among Polish students of Dutch." In: Proceedings of 2012 Language and Language Teaching Conference: 54-62.

de Louw, Robertus (forthcoming): "Is Dutch a pluricentric language with two centresof standardization? An overview of the differences between Netherlandic and Belgian Dutch from a Flemish perspective." In: Werkwinkel 11(1): forthcoming

Donmall, B. Gillian (1985): Language awareness: NCLE reports and papers, 6. CILT: London.

Ellis, Rod (1994): The study of second language acquisition. Oxford: Oxford University Press.

Ellis, Rod (2004): "The definition and measurement of L2 explicit knowledge." In: Language Learning 54, 2: 227-275.

Ellis, Rod (2005a): "Measuring implicit and explicit knowledge of a second language: A psychometric study", Studies in Second Language Acquisition, 27: 141-172.

Ellis, Rod (2005b): "Principles of instructed language learning", Asian EFL Journal 7, 3: 9-24.

Fairclough, Norman (ed.) (1996): Critical language awareness. New York: Addison Wesley Longman.

Hawkins, Eric W. (1999): "Foreign language study and language awareness." In: Language Awareness 8, 3-4: 124-142.

James, Carl / Peter Garrett (ed.) (1991): Language awareness in the classroom. Burnt Mill: Longman.

Jaspers, Jürgen (2001): “Het Vlaamse stigma: Over tussnentaal en normativiteit.” In:Taal en Tongval 53, 2: 129-153.

Kellerman, Eric (1977): "Towards a characterization of the strategies of transfer in second language learning." In: International Studies Bulletin 2: 58-145.

Krashen, Stephen D. (1981): Second language acquisition and second language learning. Oxford: Pergamon Press.

Leow, Ronald P. (1997): “Attention, awareness and foreign language behavior." In: Language Learning 47: 467-506.

Leow, Ronald P. (2000): "A study of the role of awareness in foreign language behavior: Aware vs. unaware learners." In: Studies in Second Language Acquisition 22: 557-584.

Leow, Ronald P. (2006): "The role of awareness in L2 development: Theory, research and pedagogy." In: Indonesian Journal of English Language Teaching 2/2: 125-139.

Loft (2008): film directed by Erik Van Looy. Woestijnvis.

Loft (2010): film directed by Antoinette Beumer. Millstreet Films.

O'Malley, J. Michael / Anna Uhl Chamot (1990): Learning strategies in second language acquisition. Cambridge: Cambridge University Press.

Paradis, Michel (2004): A neurolinguistic theory of bilingualism. Amsterdam: John Benjamins.

Paradis, Michel (2009): Declarative and procedural determinants of second languages. Amsterdam: John Benjamins.

PE Author (2010): "Nederlandse paars-plus onderhandelingen worden moeilijk." In: DeMorgen, 5 July 2010. Last accessed on 13.01.2015. <http://www.demorgen.be/dm/nl/990/Buitenland/article/detail/1129239/ 2010/07/05/Nederlandse-paars-plus-onderhandelingen-worden-moeilijk. dhtml>.

Pinto, Maria Antonietta et al. (1999): Metalinguistic awareness: Theory, development and measurement instruments. Pisa: Istituti editoriale e poligrafici internazionali.

Rebuschat, Patrick / John N. Williams (2012): "Implicit and explicit knowledge in second language acquisition.” In: Applied Psycholinguistics 33, 4: 829-856.

Neerlandica Wratislaviensia 26, 2016

(C) for this edition by CNS 
Richards, Jack C. et al. (1992): Longman dictionary of language teaching and applied linguistics (2nd edition) Harlow: Longman.

Richards, Jack C. / Richard Schmidt (2010): Longman dictionary of language teaching and applied linguistics. (4th edition.) Harlow: Longman.

Schmidt, Richard W. (1990): "The role of consciousness in second language acquisition." In: Applied Linguistics 11, 2: 129-158.

Schmidt, Richard (2001): “Attention.” In: Peter Robinson (ed.), Cognition and second language instruction. Cambridge: Cambridge University Press, 3-32.

Scollon, Ron / Suzanne Wong Scollon (2001): Intercultural communication. A discourse approach. Malden, MA: Blackwell.

Svalberg, Agneta M-L. (2007): "Language awareness and language learning." In: Language Teaching 40: 287-308.

Thornbury, Scott (1997): About language. Cambridge: Cambridge University Press.

Vandekerckhove, Reinhild (2005): "Belgian Dutch versus Netherlandic Dutch: New patterns of divergence? On pronouns of address and diminutives," In: Multilingua 24: 379-397.

Vandekerckhove, Reinhild (2007): "Tussentaal' as a source of change from below in Belgian Dutch: A case study of substandardization processes in the chat language of Flemish teenagers." In: Stephan Elspass et al. (eds.), Germanic language histories 'from below' (1700-2000). Berlin: De Gruyter, 189-203.

van Essen, Arthur (2008): "Language awareness and knowledge about language: A historical overview." In: Jasone Cenoz / Nancy H. Hornberger (eds.), Encyclopedia of language and education (2nd edition). Vol. 6: Knowledge about language. New York: Springer, 3-14.

van Lier, Leo (1995): Introducing language awareness. London: Penguin Books.

Williams, John N. (2004): "Implicit learning of form-meaning connections." In: Bill van Patten et al. (eds.), Form-meaning connections in SLA. Mahwah: Lawrence Erlbaum Associates, 203-218.

Zot van A. (2010): film directed by Jan Verheyen. Eyeworks \& TV Drama. 